\title{
Perancangan Infografis Tentang Kesadaran Tertib Lalu Lintas di Kota Mataram
}

\author{
Qaolan Jadid Subardan'1, Sandi Justitia Putra*2, I Nyoman Yoga Sumadewa ${ }^{3}$ \\ 1,2,3Program Studi Desain Komunikasi Visual, Fakultas Teknik dan Ilmu Komputer, Universitas Bumigora \\ *e-mail: Olanjadid96@gmail.com ${ }^{1}$, sandi.justitia@universitasbumigora.ac.id ${ }^{2}$
}

\begin{abstract}
The very high growth of vehicles in the City of Mataram is not matched by public awareness of the importance of a good and correct traffic order in accordance with applicable regulations. This problem is what makes traffic accidents occur every year and continue to grow. The need for appropriate and appropriate new media that is out of the box or unusual for the public. So through this dedication activity, the service team will create an infographic work by applying ambient media to be the right media to socialize orderly awareness in traffic by displaying data about traffic accidents in the previous year. This work uses a design thinking methodology. The conclusion is that this infographic work provides a memorable experience for road users and evokes feelings and moods for the target audience to feel comfortable and happy when interacting with the work of the infographic.
\end{abstract}

Keywords: Infographics, Ambient, Orderly awareness of traffic

\begin{abstract}
Abstrak
Pertumbuhan kendaraan di Kota Mataram yang sangat tinggi tidak diimbangi dengan kesadaran masyarakat tentang pentingnya tertib berlalu lintas yang baik dan benar sesuai dengan peraturan yang berlaku. Permasalahan inilah yang membuat kecelakaan lalu lintas tiap tahunnya terjadi dan terus bertambah. Dibutuhkannya media baru yang tepat dan sesuai yang berisfat out the box atau tidak biasa kepada masyarakat. Maka melalui kegiatan pengabdian ini tim pengabdi akan membuat sebuah Karya infografis dengan penerapan ambient media menjadi media yang tepat untuk mensosialisasikan tentang kesadaran tertib dalam berlalu lintas dengan cara menampilkan data-data tentang kecelakaan lalu lintas pada tahun sebelumnya. Karya ini menggunakan metodologi design thinking. Kesimpulannya adalah karya infografis ini memberikan memorable experience kepada pengguna jalan dan membangkitkan feeling dan mood kepada target audiens agar merasa nyaman dan suka ketika berinteraksi dengan karya dari infografis tersebut.
\end{abstract}

Kata kunci: Infografis, Ambient, Kesadaran tertib berlalu lintas

\section{PENDAHULUAN}

Kesadaran masyarakat tentang pentingnya berlalu lintas yang benar semakin berkurang. Banyak masyarakat yang kurang memahami pentingnya pemahaman tentang berlalu lintas yang baik dan benar sesuai peraturan. Hal ini sangat disayangkan sekali karena pentingnya masyarakat sadar akan lalu lintas ini akan bisa membawa hal positif dalam keselamatan berkendara. Keselamatan berkendara inilah yang diperlukan masyarakat Kota Mataram untuk mengurangi tingkat kecelakaan dalam berlalu lintas (https://ditlantas.ntb.polri.go.id/tanggal 23/04/2019 Pukul 21.13 PM).

Pertumbuhan kendaraan di NTB sangat luar biasa, sekarang masyarakat membeli kendaraan sangat mudah dan banyak. Di satu sisi hal ini menunjukkan bahwa perekonomian dan daya beli masyarakat khususnya di NTB meningkat dengan baik, namun di sisi lain menjadi memprihatinkan karena pertumbuhan kendaraan ini tidak diimbangi dengan kesadaran masyarakat tentang bagaimana berlalulintas yang baik dan benar sesuai peraturan tata tertib lalu lintas yang berlaku.

Data Ditlantas Polda NTB Polres Mataram pada Kota Mataram menyebutkan, lakalantas yang terjadi di tahun 2017 tercatat kasus lakalantas dengan 204 kasus dengan catatan 40 korban meninggal. Pada tahun 2018, jumlah kasus kecelakaan lalulintas di Kota Mataram mencapai 267 
dengan catatan sepeda motor sebanyak 355 kasus dan kendaraan roda empat 117 kasus. Sedangkan yang meninggal dunia sebanyak 75 korban dengan kerugian material sebesar 70 juta rupiah. Ada 3 hal yang menjadi masalah berlalu lintas yaitu, kemacetan, pelanggaran, dan kecelakaan lalu lintas.

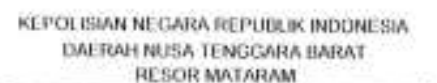
PESOR MUIARMM

\begin{tabular}{|c|c|c|c|c|c|c|}
\hline \multirow{3}{*}{ No } & \multicolumn{6}{|c|}{ JUNEAH LAKA LANTAS TAHUN 2019} \\
\hline & \multirow{2}{*}{ BULAN } & \multirow{2}{*}{$\begin{array}{l}\text { JUML.AH } \\
\text { LAKA }\end{array}$} & \multicolumn{3}{|c|}{ JUMLAH KORBAN LAKA LANTAS } & \multirow{2}{*}{ KEAMAT } \\
\hline & & & No & LB & $L R$ & \\
\hline 1 & IMNUARII & 20 & 2 & D & 22 & 5.2000000 \\
\hline 2 & FEBRLMAI & 19 & 3 & 0 & 21 & 3750000 \\
\hline $\mathbf{3}$ & MARET & 15 & i & 0 & 13 & 3800000 \\
\hline 4 & APRA & 25 & 6 & 0 & 28 & 6750000 \\
\hline 5 & MEI & 16 & 11. & 0 & $\theta$ & 8950000 \\
\hline 6 & JUNI & 24 & a & 0 & 24 & $8.050,000$ \\
\hline 7 & 2011 & 25 & 11 & 0 & 22 & E. 500000 \\
\hline 8 & Agustus & 12 & 2 & 0 & 14 & 1700000 \\
\hline 9 & SEPTEMBER & 22 & 5 & 0 & 20 & 6200000 \\
\hline 10 & OKTCAEA & 28 & 5 & 0 & 32. & 5950000 \\
\hline 11 & NONEMBER & $2 \theta$ & 10 & 0 & 21 & 6500000 \\
\hline 12 & DESEMEEด & 33 & $\theta$ & 0 & 34 & 8250000 \\
\hline & JUMLAH TOTAL & 267 & 75 & 0 & 260 & 69.300 .000 \\
\hline
\end{tabular}

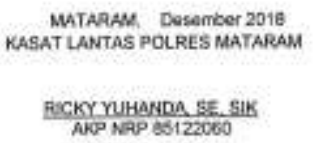

Gambar 1. Data Kerugian Akibat Lakalantas 2018

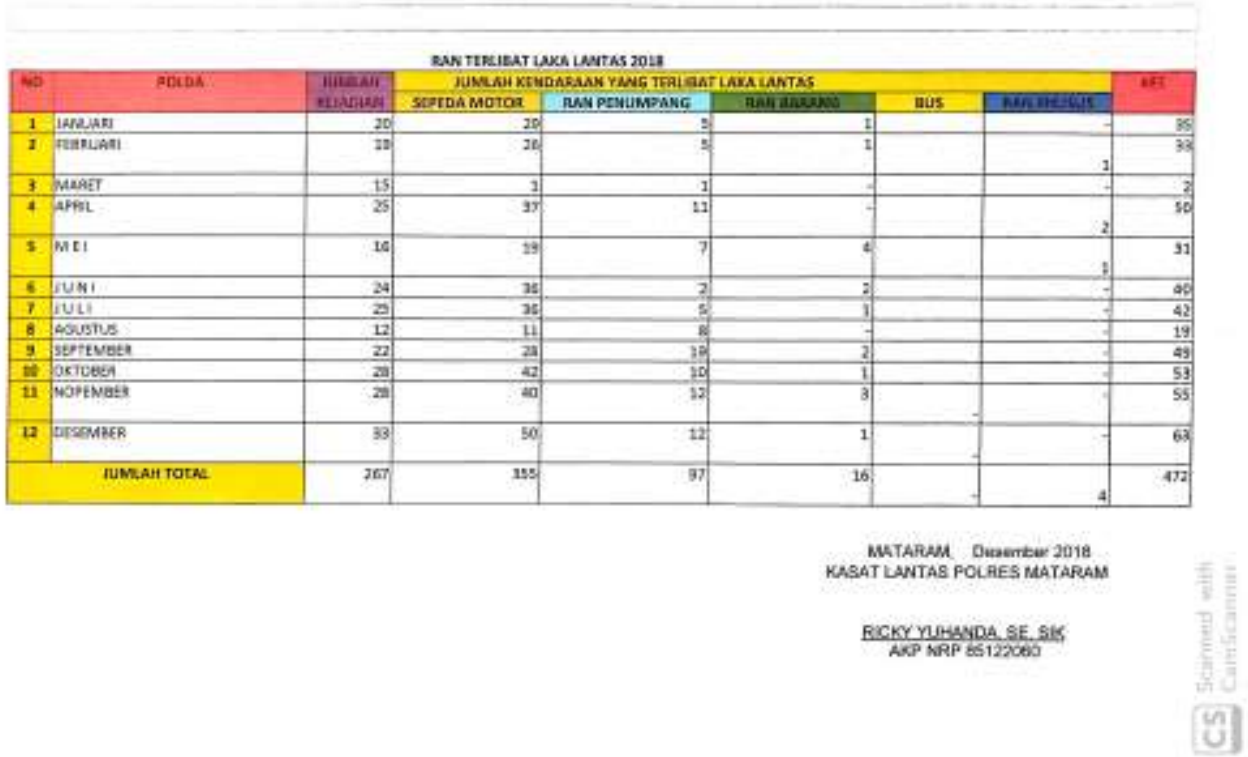

Gambar 2. Data Lakalantas 2018

Infografis adalah bagian dari informasi visual, peranannya adalah memperesentasikan data-data, angka, naskah, grafik, diagram dan peta. Istilah infografis dalam jurnalistik lebih dikenal dengan sebutan visual journalism, infografis dalam surat kabar menjadi bagian penting untuk menyampaikan sesuatu permasalahan berita kedalam bentuk visual. Pengertian infografis menurut Glasgow ialah infografis sering disebut pula sebagai ilustrasi visual sebuah informasi (Glasgow, 1994:7). 
Ambient Media merupakan salah satu strategi beriklan yang tujuan utamanya adalah untuk membangkitkan feeling dan mood konsumen agar merasa nyaman dan suka ketika berinteraksi dengan produk atau layanan yang ditawarkan oleh produsen. Semangat yang dibawa oleh ambient media adalah memberikan memorable experience kepada konsumen. Dalam perkembangannya ambient media menjadi sebuah kegiatan below the line yang terintegrasi dengan media. Ambient media juga disebut sebagai media lingkungan (Lwin dan Aitchison:2002).

Dari latar belakang di atas tim pengabdi menyimpulkan bahwa kesadaran tertib dalam berlalu lintas masih diperlukan oleh masyarakat dalam berkendara di Kota Mataram, karena sampai sekarang masih banyak terjadi kecelakaan lalu lintas karena kelalaian masyarakat dalam berkendara dan kurangnya kesadaran tertib berlalu lintas. Infografis memiliki peranan yang sangat penting dalam hal ini. Karena, masih banyak masyarakat di Indonesia khususnya di Kota Mataram yang tidak peduli akan penting nya kesadaran lalulintas. Maksud dan tujuan dari kegiatan perancangan ini adalah untuk mensosialisasikan tentang kesadaran lalu lintas kepada masyarakat menggunakan media infografis dengan pendekatan ambient media.

\section{METODE}

Dalam kegiatan perancangan ini, tim pengabdi akan menggunakan metode Design Thinking yang merupakan metode penyelesaian masalah yang berfokus ke pada pengguna. Design thinking dipopulerkan oleh David Kelley dan Tim Brown pendiri IDE0, sebuah konsultan desain yang berlatar belakang desain produk berbasis inovasi.

Menurutnya Design Thinking merupakan metode penyelesaian masalah yang berfokus ke pada pengguna, adapun beberapa metode dalam design thinking:

a. Empathize

Ketika sudah mengetahui target audiens yang akan di tuju, maka penulis akan perlu mengetahui pengalaman, emosi, dan situasi dari target audiens. Mencoba menempatkan diri sebagai target audiens sehingga dapat benar-benar memahami kebutuhan target audiens. Hal ini dapat dilakukan dengan cara wawancara, observasi terhadap target audiens dan cara lainnya.

b. Define

Setelah penulis mengumpulkan informasi target audiens dari Empathize, penulis kemudian menggambarkan ide-ide atau gagasan konsep yang menjadi dasar dari apa yang akan dibuat. Hal ini dapat dilakukan dengan cara membuat suatu list daftar kebutuhan penulis dan menggunakan pengetahuan mengenai yang sedang terjadi.

c. Ideate

Merealisasikan ide kreatif yang sudah didapat dari tahapan define. Dalam proses memunculkan ide menggunakan mindmaping penulis menggambarkan solusi yang dibutuhkan.

\section{d. Prototype}

Seteleah ide kreatif ditentukan kemudian buatlah rancangan prototype dari ide tersebut dan mengimplementasikan ide kreatif tersebut.

e. Test

Setelah itu, kemudian lakukan testing kepada target audiens dari hasil perancangan prototype ini untuk mengukur seberapa efektif ide yang dimiliki agar dapat mengahasilakn yang terbaik.

\section{HASIL DAN PEMBAHASAN}

Konsep desain atau kreatif yang menjadi kata kunci adalah simple ambient media. Penempatan visual dan informasi dalam Infografis secara simple ambient media pada setiap persimpangan lalu lintas di zebra cross yang di tuju dan menarik perhatian dari target audiens dengan memaparkan visualisasi Jumlah kasus kecelakaan, korban jiwa dan kerugian yang terjadi di lalu lintas Kota Mataram dengan menambahkan beberapa komponen visualisasi yang simple di jalan tersebut serta beberapa data statistik yang diperlukan. 
a. Target Audiens

Adapun target audiens yang dituju adalah Pelajar, Mahasiswa, dan masyarakat umum yang rentan usia 18 Tahun hingga keatas (pengguna jalan yang yang sudah memiliki KTP dan SIM). Berjenis kelamin Laki-laki dan perempuan.

b. Definisi Operasional

Dalam perancangan ini dari segi subjek bertujuan untuk terciptanya Infografis tentang kesadaran berlalu lintas, terciptanya karya rancangan infografis dengan pendekatan ambient media. Infografis yang dibuat tentang menampilkan konten-konten dan data-data yang berkaitan dengan lalulintas. Maksudnya pendekatan ambient media ini bertujuan untuk membangun interaksi antara pengguna jalan dengan media infografis tersebut, agar mengena inti dari pesan yang ingin disampaikan. Infografis ini dibuat agar masyarakat mengetahui dan memahami tentang kesadaran tertib dalam berlalulintas. Dalam berlalulintas pentingnya suatu informasi yang akurat untuk mengetahui peraturan-peraturan dalam berkendara, tidak hanya menggunakan media, namun juga pentingnya penempatan suatu media tersebut dengan menggunakan pendekatan ambient media.

Oleh karena itu, dengan adanya infografis dengan pendekatan ambient media ini diharapkan dapat menjangkau masyarakat dan terciptanya kesadaran dalam berlalu lintas sehingga mengurangi tingkat kecelakaan lalu lintas pada Kota Mataram.

c. Pengarahan Pesan Visual

1) TipeTipografi

Jenis huruf atau tipografi yang digunakan pada infografis ini adalah jenis font san serif. Anatomi dari jenis san serif ini tidak memiliki garis-garis kecil dan bersifat solid. Kesan yang ditimbulkan lebih tegas, bersifat fungsional dan lebih modern. Jenis font ini sangat cocok pada infografis ini, karena memaparkan data tentang korban dan kecelakaan dalam berlalu lintas sehingga target audiens jelas dalam membaca informasinya. Untuk itu, penulis memilki beberapa type face yang cocok dan tepat dengan tema yang di angkat, antara lain:

a) BEBAS

\section{ABCDEFGHJKLMNOPC RSTUNWXYZ 1234567890}

Nantinya jenis font yang di atas ini digunakan pada kalimat slogan, pada kata-kata yang dibutuhkan untuk menunjukkan data pada infografis seperti, jumlah kecelakaan, korban meninggal dan kerugian serta angka-angka yang dibutuhkan.

b) Milestone One



Jenis font ini nantinya akan digunakan pada kata: Bodycopy, Judul, Closing 
2) Tone Warna

Menggunakan warna-warna cerah dan sedikit beberapa warna gelap pada infografi s ini. Warna-warna ini adalah warna yang selaras dengan warna traffic light, dimana warna-warna ini memiliki kontras yang cerah sehingga kesan yang ingin ditunjukkan semangat yang dapat menarik perhatian audiens dan mudah diingat, dilihat dan, dibaca oleh target audiens.

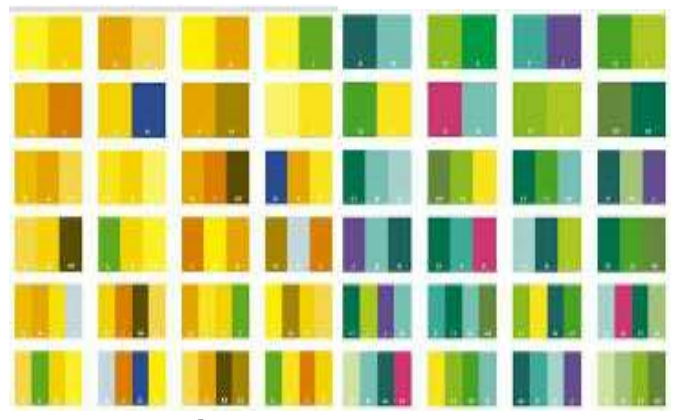

Gambar 3. Tone Warna

(Pinterest, 2019)

\section{3) Layout}

Sebagai pendukung dari citra visual infografis simple ambient media ini yang menyatu dengan media pendukung nya yaitu zebra cross, penataan dari elemen-elemen visual dan data informasinya juga harus sesuai dan mendukung. Oleh karena itu, elemen visual dari infografis ini diatur rapi pada garis-garis putih zebra cross yang berarti penataan harus seimbang atau biasa disebut balance yang artinya stabilitas atau kesan adanya daya tarik yang sama antara bagian yang satu dengan yang lainnya atau yang menjadi pusat perhatian pada susunan desain yang dibuat. Contoh layout yang menjadi referensi penulis, antara lain:

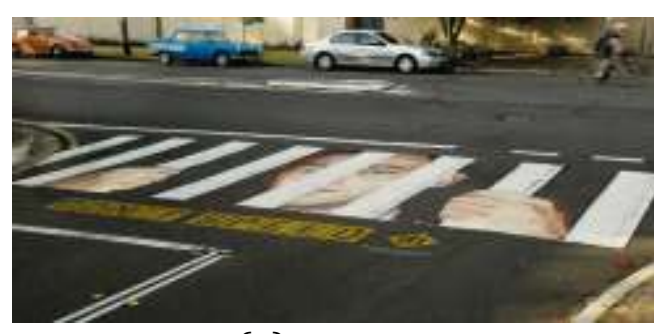

(a)

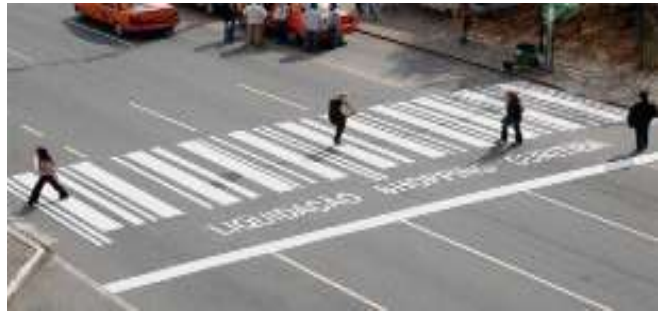

(b)

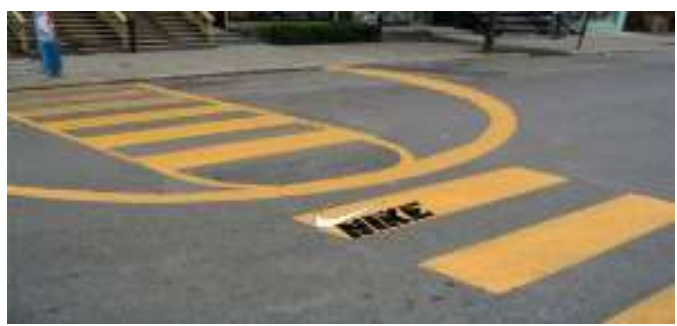

(c)

Gambar 4. $(\mathrm{a}+\mathrm{b}+\mathrm{c})$ Layout

(Pinterest, 2019)

4) Model Ilustrasi

Model ilustrasi yang akan dibuat pada infografis yang memanfaatkan penempatan pada zebra cross ini, menggambarkan siluet orang tergeletak di jalan dan beberapa komponen visual-visual akibat dari menerobos dengan gaya flat design yang digambarkan pada tengah garis-garis putih pada zebra cross di persimpangan lalu 
lintas yang menjadi target. Tidak lupa memaparkan data-data statistik korban kecelakaan pada infografis ini.

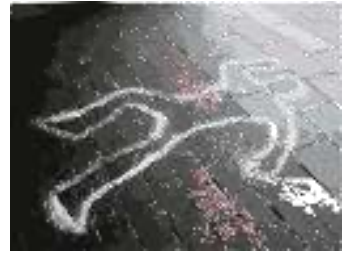

(a)

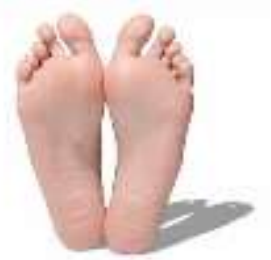

(c)

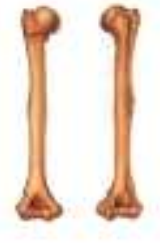

(d)



(b)

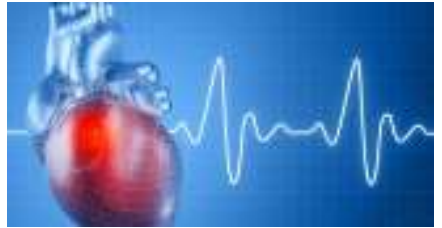

(e)

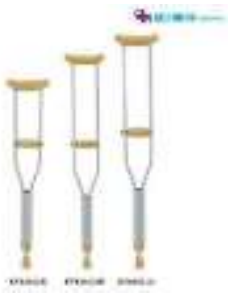

(f)

Gambar 5. $(\mathrm{a}+\mathrm{b}+\mathrm{c}+\mathrm{d}+\mathrm{e}+\mathrm{f})$ Model Ilustrasi

(Pinterest, 2019)

\section{d. Desain Siluet}

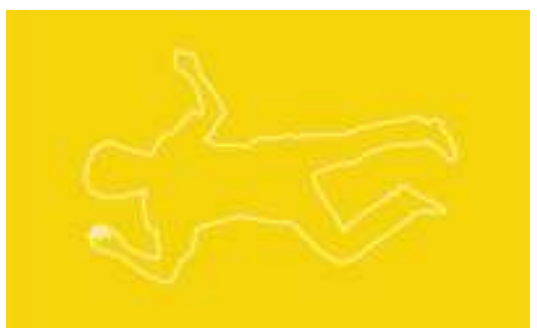

Gambar 6. Desain Siluet

Pada gambar atau foto orang tergeletak di atas disederhanakan sehingga membentuk siluet yang berwarna kemudian menjadi bagian stroke saja yang dimana konsep dari desain karya yang dinginkan sesuai yaitu desain yang simple dan sederhana.

\section{e. Desain Diagram}

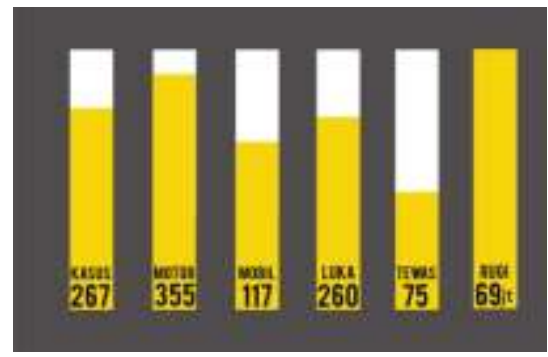

Gambar 7. Desain Diagram

Diagram diatas merupakan visual dari zebra cross yang berada pada persimpangan lalu lintas di Kota Mataram. Diagram tersebut terlihat seperti naik turun namun ada batas diagram atau zebra cross itu sendiri yang menjadi batas dari diagram atau data yang akan ditetapkan, selain itu data diterapkan pada bagian bawah diagram tersebut. 


\section{f. Desain Visual}

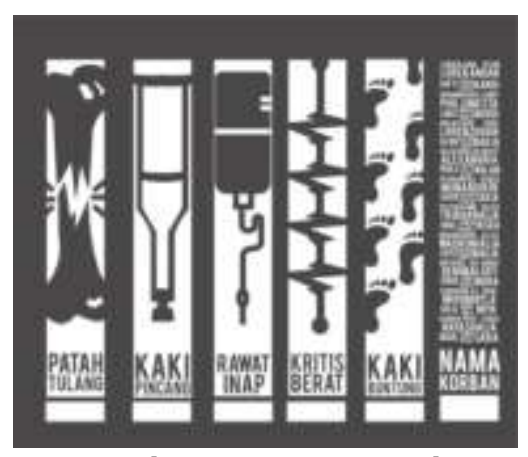

Gambar 8. Desain Visual

Pada karya infografis yang kedua ini penulis membuat visualisasi resiko atau akibat dampak dari melanggar ataupun menerobos lalulintas. Visual-visual yang diterapkan antara lain. Visual tulang patah yang mempresentasikan patah tulang yang terjadi, selanjutnya tongkat yang mempresentasikan bahwa tongkat tersebut visual dari kaki pincang. Kemudian ada visual infus yang mempresentasikan korban yang melanggar lalu lintas akan di rawat inap pada rumah sakit. Selanjutnya visual garis-garis seperti detak jantung yang mempresentasikan korban tersebut mengalami keadaan kritis. Selanjutnya visual telapak atau jejak kaki kiri tanpa adanya kaki kanan yang mempresentasikan korban mengalami kaki buntung dan terakhir merupakan beberapa nama-nama korban yang melanggar dan menerobos. Untuk penerapannya, desain ini diterapkan pada zebra cross persimpangan lalu lintas di Kota Mataram.

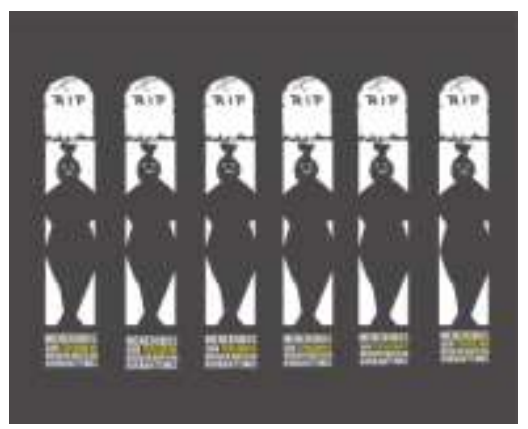

Gambar 9. Desain Visual

Pada karya infografis yang ketiga ini penulis menggunakan konsep visual pocong yang dimana konsep ini bertemakan horor namun dengan ekspresi bernuasa humor yang diterapkan pada zebra cross tersebut sebagai tempat penerapannya. Pada bagian atas juga terdapat nisan yang digambarkan retak dan bertuliskan R.I.P untuk menandakan bahwa adanya korban tewas, serta pada bagian bawah terdapat sebuah kalimat yang mengakibatkan korban tewas. Desain ini lebih menyatu dengan objek zebra cross tersebut yang dimana seolah zebra cross tersebut membentuk sebuah pocong.

\section{g. Final Layout}

Dari komponen-komponen desain sebelumnya yang telah di bahas dan dibuat pada layout kasar dan layout komprehensif, kemudian penulis menggabungkan komponen tersebut sehingga dapat merancang hasil akhir dari desain layout yang akan digunakan pada karya infografis dalam penerapan ambient yang akan dilakukan pada persimpangan lalu lintas di Kota Mataram. 


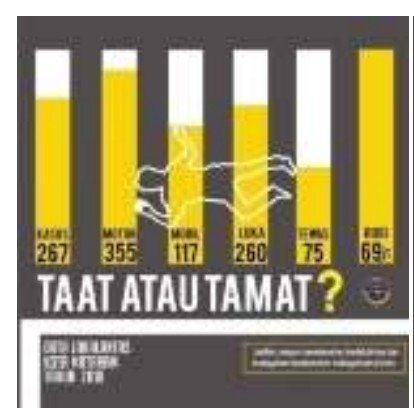

(a)



(b)

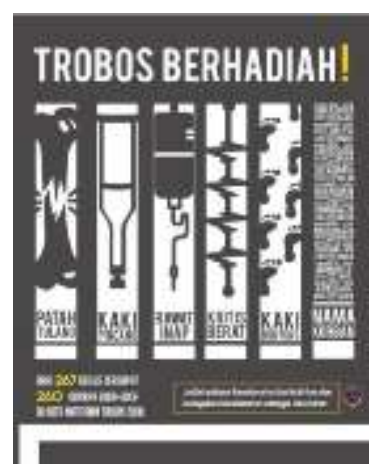

(c)

Gambar 10. $(a+b+c)$ Final Layout

Dari desain ini terliha gaya desain yang memang ingin di tonjolkan adalah flat desain dan citra visual yang di tunjukkan dalam keseluruhannya adalah simple, sederhana dan unik. Sehingga konsep atau Big Idea yang ingin di tunjukkan sesuai yang sebelumnya di bahas dalam konsep perancangan dan kreatif yaitu, simple ambient media. Karya infografis dengan pendekatan ambient media ini berjumlah 3 karya.

\section{h. Hasil MockUp}

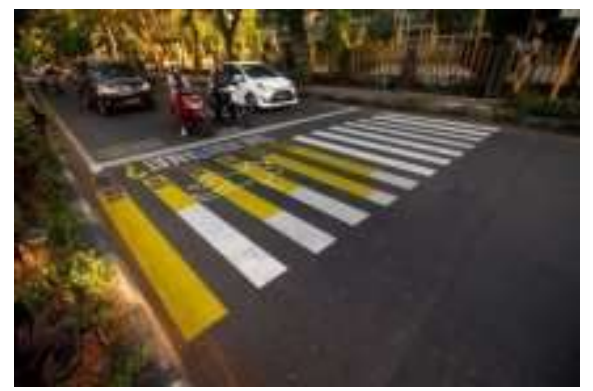

(a)

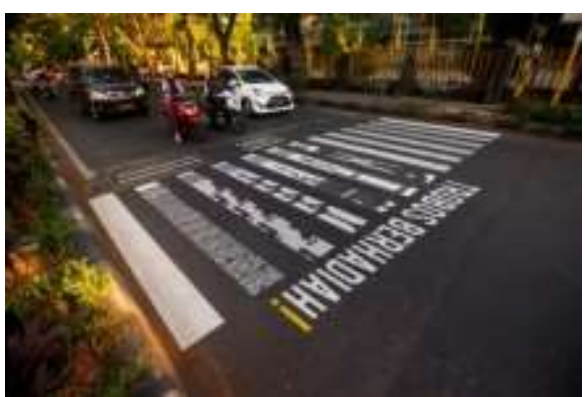

(b)

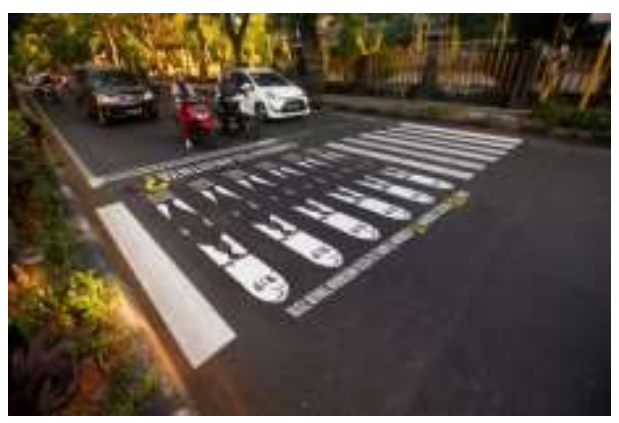

(c)

Gambar 11. $(a+b+c)$ Hasil MockUp persimpangan jl. Sriwijaya 


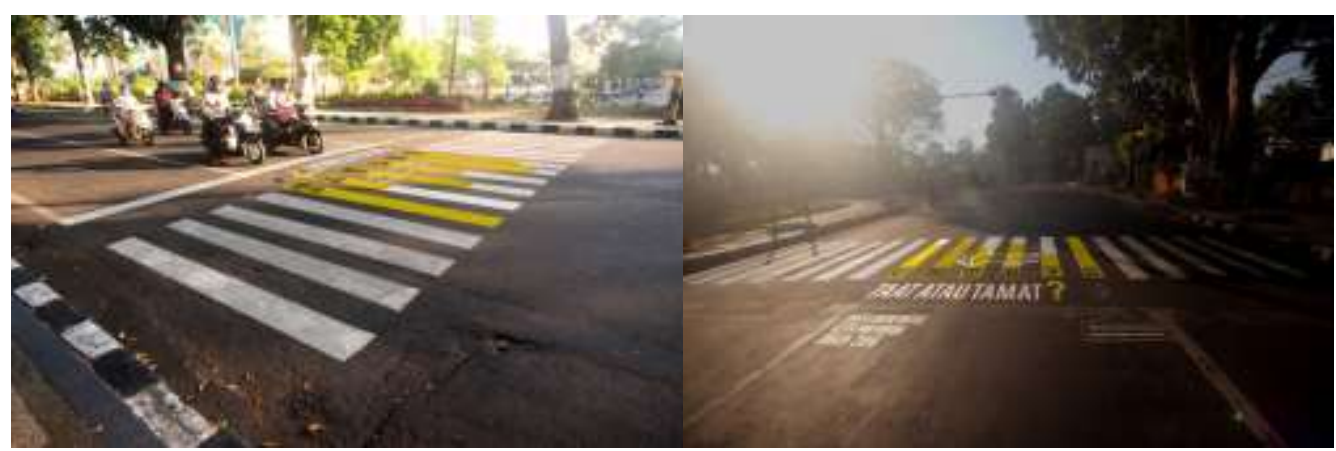

(a)

(b)

Gambar 12. $(\mathrm{a}+\mathrm{b})$ Hasil MockUp persimpangan pada jalan Islamic Center



(a)

(b)

Gambar 13. $(\mathrm{a}+\mathrm{b})$ Hasil MockUp jalan pendopo walikota Kota Mataram

i. Media Pendukung

Pada tahap ini merupakan tahap dimana suatu karya yang menjadi media utama harus dapat di dukung oleh media pendukung yang bertujuan untuk menggiring target audiens yang dituju untuk dapat menjangkau karya utama.
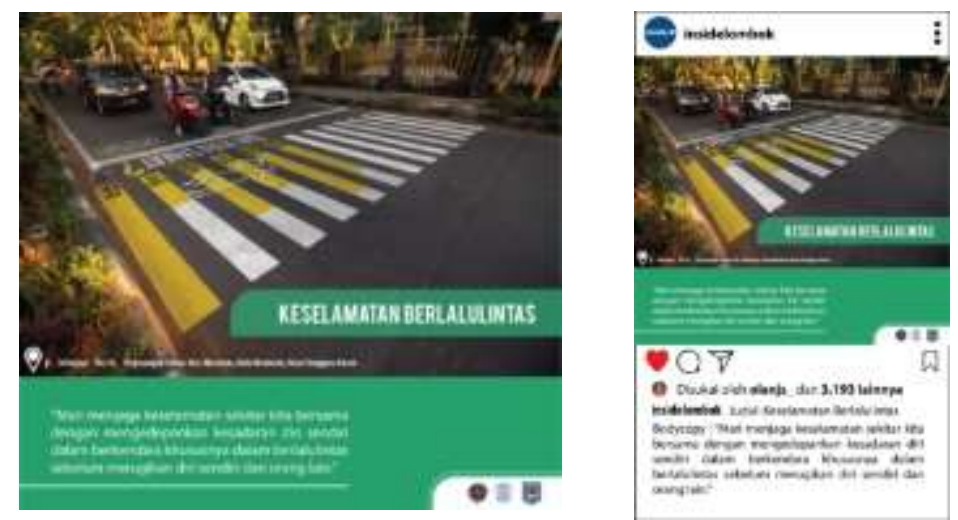

Gambar 14. Media Pendukung

Pada poster ini terdapat judul dan bodycopy atau isi dari karya infografis. Dalam poster ini terdapat foto hasil dari penerapan karya infografis yang bertujuan untuk menjangkau target audiens dan menggiring ketempat dimana karya infografis tersebut di terapkan. Desain ini merupakan desain akhir poster yang akan digunakan dan di publikasikan melalui sosial media instagram pada akun @insidelombok. 


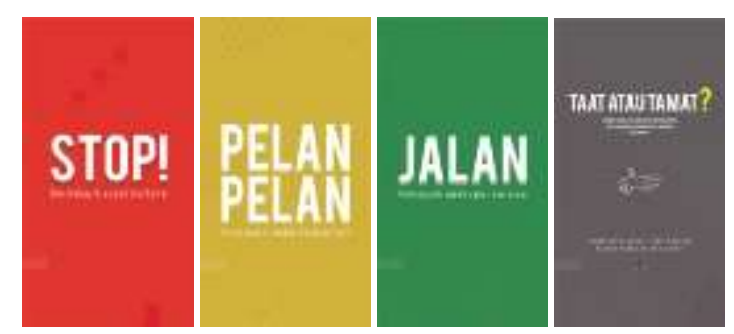

Gambar 15. Media Pendukung

Desain ini bertujuan untuk membuat target audiens seolah-olah berada pada situasi mengantri di traffic light saat membaca dan dapat mengerti bahwa informasi tersebut bertujuan untuk memberitahukan dan mengingatkan kembali fungsi dari warna-warna traffic light tersebut agar kedepannya lebih sadar dalam keselamatan tertib berlalu lintas.



Gambar 16. Media Pendukung

j. Dokumentasi kegiatan observasi lokasi oleh tim pengabdi

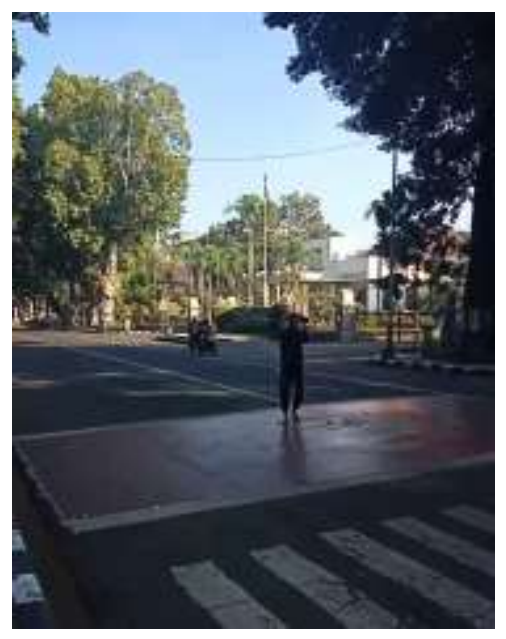

(a)

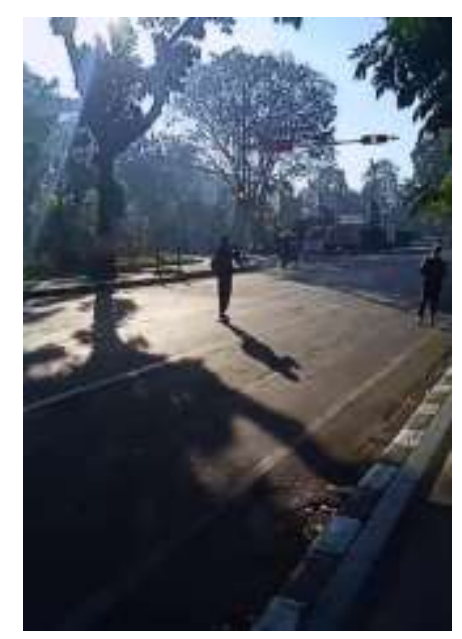

(b)

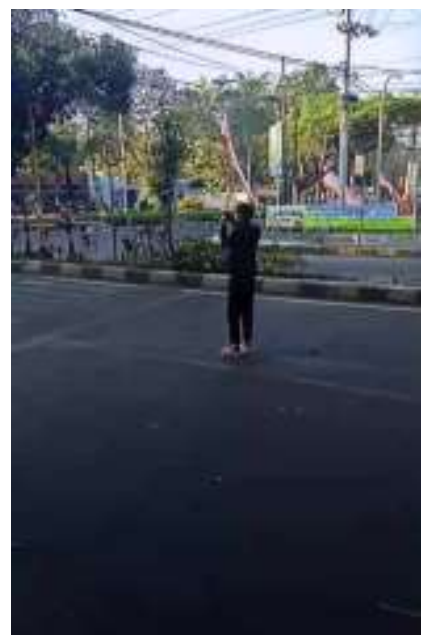

(c)

Gambar 17. (a) jalan pendopo walikota Kota Mataram (b) persimpangan jalan Sriwijaya (c) persimpangan pada jalan Islamic Center

\section{KESIMPULAN}

a. Karya dari kegiatan perancangan ini berupa karya infografis tentang kesadaran tertib dalam berlalu lintas di Kota Mataram. 
b. Karya infografis ini menggunakan metodologi design thinking, karena metode ini merupakan metode dalam menciptakan media yang tepat untuk menjangkau target audiens dengan cara yang tidak biasa atau biasa di sebut dengan out of the box.

c. Sebelum menemukan konsep kreatif, tim pengabdi telah melakukan mind mapping untuk mencari big idea pada karya infografis tersebut. Big idea yang ditemukan penulis adalah simple ambient media, yaitu karya infografis yang penempatan karyanya langsung diterapkan pada objeknya yaitu pada persimpangan lalulintas di area zebracroos.

d. Karya infografis ini menggunakan pemilihan warna-warna cerah ataupun terang dan warna yang berkaitan dengan warna traffic light yang berguna untuk menarik perhatian target audiens. Gaya desain yang digunakan pada karya infografis ini adalah flat design yang dimana gaya ini merupakan gaya desain yang simple dan sederhana sehingga target audiens dapat dengan mudah untuk bisa melihat dan membaca informasi yang tertera.

e. Citra visual yang ditunjukkan pada infografis simple ambient media ini adalah unik. Oleh karena itu, karya infografis ini memberikan memorable experience kepada pengguna jalan atau pengendara dan dapat membangkitkan feeling dan mood kepada target audiens agar merasa nyaman dan suka ketika berinteraksi dengan karya dari infografis tersebut.

f. Terciptanya karya infografis yang informatif dan komunikatif sehingga diharapkan akan mampu menurunkan jumlah kecelakaan lalu lintas di Kota Mataram.

\section{UCAPAN TERIMA KASIH}

Tim Penulis mengucapkan terima kasih kepada Pemerintah Kota Mataram dan Universitas Bumigora yang telah mendukung terlaksananya kegiatan pengabdian ini. Serta untuk Universitas Lancang Kuning Pekanbaru yang telah berkenan menerbitkan kegiatan pengabdian ini dalam DINAMISIA; Jurnal Pengabdian Kepada Masyarakat Universitas Lancang Kuning.

\section{DAFTAR PUSTAKA}

Aspen, Angga Rahmadinata. (2017). Perancangan Infografis Panduan Siaga Bencana Gempa dan Tsunami pada Media Booklet. UNP: Jurnal

Bayuargo, Febrian Satria. (2015). Perancangan Infografis Tentang Kesadaran Lalu Lintas. Institut Seni Indonesia Yogyakarta: Jurnal

Canagara, Hafied. (2006). Pengantar Ilmu Komunikasi. Jakarta: PT Raja Grafindo Persada

Darmaprawira, Sulasmi W.A. (2002). Warna: Teori dan Kreativitas Penggunaannya. Bandung: ITB

Daryanto. (1993). Media Visual Pengajaran Teknik. Tarsito: Bandung

Ditlantas Polda NTB. (2017). Kesadaran tentang Pentingnya Berlalulintas yang Baik, diakses dari https://ditlantas.ntb.polri.go.id/

Fakultas Psikologi. (2015). Teori Kepribadian Sigmund Freud, diakses dari https://psikologi.ustjogja.ac. id/index. php/2015/11/05/teori-kepribadian-sigmundfreud/

Hendika Setiabudi, Heri Iswandi dan Bobby Halim. (2016). Pada judul skripsi tentang Perancangan Kampanye Sosial Tertib dan Aman Berlalu Lintas. Universitas IndoGlobal Mandiri: Jurnal

ID Pengertian. (2018). Pengertian Iklan Layanan Masyarakat, diakses dari https://www.idpengertian.com/pengertian-iklan-layanan-masyarakat/

Jefkins, Frank. 1997. Periklanan. Jakarta: Erlangga.

Kasali, Rhenald. (1992). Manajemen Periklanan Konsep dan aplikasinya Di Indonesia. Jakarta: Pustaka Utama Grafiti 
Kasiram, Moh. (2008). Metodologi Penelitian Kualitatif dan Kuantitatif. Malang: UIN-Malang Pers.

Kominfo. (2018). Kiat Bikin Infografis Keren dan berkualitas baik. Indonesiabaik.id

Lankow, Ritchie, dan Crooks. (2014). Infografis Kedasyatan Bercerita Visual, Jakarta: PT. Gramedia Pustaka

Lexy J. Moleong. (2005). Metodologi penelitian kualitatif, Bandung: Remaja Rosdakarya

Lwin May \& Aitchison Jim. (2002). Clueless In Advertising (Rajoe Paul, Trans.). Jakarta: Bhuana Ilmu Populer.

Multimedia. (2013). Pengertian Desain Grafis, diakses dari http://manpras.blogspot. com/2013/02/pengertian-desaingrafis.html

Munawar, Ahmad. (2004). Manajemen Lalu Lintas Perkotaan. Jogjakarta: Jalasutra.

Nugraha Yogis Pratama Putra, Mery Tania, Nurul Iklima, dan Danar Lingga Maulana. (2017). Perancangan Infografis Tentang Dampak Kebiasaan Begadang Terhadap Pola Tidur Sehat Bagi Remaja. BSI: Jurnal

Pemerintah Kota Mataram. (2017). Sejarah Kota Mataram, diakses dari Mataramkota.go.id

Sachari, Agus. (2005). Pengantar Metode Penelitian Budaya Rupa (Desain, Arsiteksur, Seni Rupa, dan Kriya), Jakarta: Erlangga.

Sarah Trenholm, Arthur Jensen. (1988). Interpersonal Communication. Inggris: Oxford University Press.

Shannon, Weaver. (1949). The Mathematical Theory of Communication. Los Angeles: SAGE Publication

Sudiana, Dendi. (2001). Pengantar Tipografi. Bandung: Rumah Produksi Dendi Sudiana

Tinarbuko, Sumbo. 2015. Dekave Desain Komunikasi Visual - Penanda Zaman Masyarakat Global. Yogyakarta: Penerbit CAPS.

Wahyuningsih, Sri. (2013). Desain Komunikasi Visual. Madura: UTM PRESS.

Warpani, P. Suwardjoko. (2002). Pengelolaan Lalu Lintas dan Angkutan Jalan. Bandung: Penerbit ITB. 